\title{
O duplo como representação do mal na novela $O$ retrato, de Gogol
}

\section{Guilherme Zubaran de Azevedo*}

\begin{abstract}
Resumo: Este trabalho é decorrente de estudo realizado sobre o tema do duplo na literatura do séc. XIX. Primeiramente, será examinado o tema do duplo na perspectiva da literatura fantástica e do Romantismo - considerando que a primeira metade do século XIX foi marcada pela exploração do irracional e do tenebroso na ficção. O próprio Romantismo passa a considerar o indivíduo como um sujeito repartido em dois, em constante conflito com o seu outro. Posteriormente, será analisada a representação do duplo na novela, $O$ retrato, de Nicolai Gogol. O exame abordará o retrato como a representação maléfica do duplo, ou seja, aquilo que desperta o lado mau das pessoas.
\end{abstract}

Palavras-chave: tema do duplo; Nicolai Gogol; representação maléfica.

\begin{abstract}
This work results from a study carried out about the theme of the Double in the literature of the XIX century. First, the theme of the double in the perspective of fantastic literature and the Romanticism will be examined, considering that the first half of the XIX century was marked by the exploration of irrational and scary aspects in fiction. Moreover, in this period Romanticism starts considering people as individuals who are split in two, in constant conflict with this other side. Later, the representation of double in the novel The Portrait, by Nicolai Gogol, will be analyzed. It will approach the evil representation of the double in this novel. In other words, this paper will examine what triggers people's evil side.
\end{abstract}

Keywords: subject of the double; Nicolai Gogol; evil representation.

As representações do duplo ${ }^{1}$ remontam aos tempos mais primitivos e relacionam-se, primeiramente, com o problema da morte e suas diferentes simbologias. Além disso, a idéia da duplicidade perpassa a literatura desde os textos da Antiguidade, nos quais se trata o duplo de maneira homogênea, até o Romantismo, no século XIX, que irá explorar o irracional, apresentando um duplo heterogêneo. Dentro dessa perspectiva, encontra-se a novela, $O$ retrato, de Nicolai Gogol, que procura identificar no duplo a corrupção dos valores morais do protagonista. Com isso, tem-se a idéia da duplicidade como representação do mal.

As primeiras idéias do duplo relacionam-se intimamente com o problema da morte e com o desejo de o indivíduo permanecer vivo frente à destruição que representa o fim da vida. A morte-renascimento - concepção mais primitiva sobre esse assunto - define-se como o

\footnotetext{
* Guilherme Zubaran de Azevedo é aluno da graduação do curso de Letras da UFRGS.

${ }^{1}$ Este estudo sobre o tema do "duplo" vem sendo realizado sob a orientação da professora Ana Maria Lisboa de Mello (UFRGS).
} 
renascimento do morto humano em um ser vivo, criança ou animal. Na verdade, dentro do sistema morte-renascimento, há os mortos que se constituem como espectros do indivíduo vivo, mantendo com ele uma convivência diária, ou seja, eles são os verdadeiros duplos. Temse, como exemplo, o $\mathrm{Ka}$ egípcio, que possuí uma existência independente do corpo com o qual foi moldado. Por essa razão, o $K a$ sobrevive perante a morte do corpo. Além disso, existem narrativas antigas que representam o ser humano como sendo uma entidade maleável e que está destinada a buscar seus aspectos ambíguos- tanto benéficos como maléficos. Por fim, o duplo representa também um conflito psíquico que evidencia a desordem íntima dos protagonistas das diversas narrativas.

A partir dessas considerações, percebe-se que o tema da duplicidade remonta a tempos mais antigos. Em cada época, a noção da duplicidade do ser altera-se conforme o contexto em que se debate esse assunto. Sob uma perspectiva mais ampla, trata-se da divisão do Eu em diversas formas: os sósias, os irmãos gêmeos, o retrato, a imagem refletida no espelho, entre outras. Na Antiguidade, destacam-se a passagem bíblica de Esaú e Jacó e a peça Anfitrião, de Plauto, que apresentam o duplo, respectivamente, sob o foco dos irmãos gêmeos e do sósia. Essas narrativas caracterizam-se por não colocar em discussão a própria personalidade do indivíduo que sofre a duplicação. Na verdade, o duplo apenas substitui, momentaneamente, o protagonista que retorna ao seu estado anterior no final da história. Logo, a semelhança física entre os personagens serve apenas para usurpar a identidade do outro. Portanto, não ocorre a divisão interna do Eu. Pelo contrário, pois o personagem mantém a unidade de sua personalidade.

A quebra da unidade do ser inicia-se a partir do século XVII. Num primeiro momento, os conflitos propostos relacionam-se com a busca da identidade. Esse novo embate caracteriza-se pela procura de um Eu melhor, entre o bem e o mal. Com isso, ocorre a divisão do ser que instala uma relação ativa do indivíduo com o mundo exterior, representando assim a união de contrários.

Já no Romantismo, a representação do duplo transforma-se na figura de um Eu fragmentado. Essa perspectiva romântica tem suas raízes no idealismo filosófico, que toma como ponto de partida para reflexão não o mundo externo, mas o que se denomina como Eu, sujeito ou consciência. Além disso, o termo Doeppelgänger - cunhado por Jean-Paul Richter e consagrado pelo Romantismo - significa, literalmente, aquele que caminha ao lado, companheiro de estrada. Assim, tem-se a idéia de um duplo trágico e fatalista que se corporifica em um inimigo, ou em um adversário que precisa ser destruído. Logo, há a concretização do duplo por desdobramento, cuja forma efetua-se com a representação de dois 
indivíduos coexistindo em um mesmo espaço ficcional. Nicole Fernandez Bravo explica, ao comentar o verbete "Duplo", no Dicionário de mitos literários, o conteúdo trágico que a duplicidade sustenta:"o desdobramento, conhecimento, é sinônimo da perda de uma inocência que permitia ao homem formar um todo indivisível com a natureza. A consciência humana, com sua capacidade de desdobramento, [...], torna-se fonte de terror" (BRAVO, 1998, p. 270). A literatura fantástica - que se desenvolve dentro do Romantismo - produz a ruptura do sujeito com o mundo racional. Esse rompimento, nas palavras de Todorov, concretiza-se quando "produz-se um acontecimento que não pode ser explicado pelas leis deste [...] mundo familiar" (1975, p. 30). Assim, a representação do duplo faz uma quebra no equilíbrio racionalista, visto que a cena do ser duplicado representa o Eu que se mostra como um nãoEu.

Um dos tipos de manifestação do duplo é a união do ser vivente com o simulacro que toma a forma do retrato, do figurino e da máscara. A figura do duplo-autômato representa a deterioração do humano. Com isso, confundir os simulacros com seres reais evidencia-se como uma doença que leva o ser vivente à loucura, ao assassinato e ao suicídio. Especificamente, a representação do duplo - em um retrato que porta uma imagem com excesso de vida - provoca um sentimento assustador no personagem, pois isso significa a possibilidade do protagonista descobrir um vício oculto em sua alma. Assim, o impacto produzido pelo contato com o duplo indica um processo de autoconhecimento e, logo, uma gradual mudança no Eu. Além do mais, a crença popular atribui ao retrato - que porta uma figura com semblante muito vivo - como manifestação do diabo. Isso ocorre exatamente pelo fato de que a imagem representa algo maléfico na própria pessoa que enxerga a figura.

Em $O$ retrato, de Nicolai Gogol, será especificamente essa a característica descrita de tal representação.A narrativa apresenta um quadro que tem pintado uma figura com os olhos muito vivos, e todos que entram em contato com o retrato subvertem seus valores. Por conseguinte, o duplo como representação do simulacro, em forma de retrato, traz à consciência características ocultas da alma e, com isso, provoca medo e horror no personagem principal da narrativa.

Nicolai Gogol representa o duplo na figura do diabo, não apenas como um tema ligado à literatura fantástica. Na verdade, o escritor, cristão ortodoxo, acredita na existência do diabo e em sua interferência no mundo. Além disso, as ações praticadas pelo diabo - ou as que o representam - indicam, de certa maneira, uma visão do mundo e da representação do mal, particular do autor. O escritor constrói a figura diabólica também a partir das lendas populares que conheceu na Ucrânia, durante a sua infância. Portanto, a construção do 
demônio se faz através de certos atos e atributos peculiares. É importante observar também que a onipresença do diabo aparece unicamente em $O$ retrato e, em outras obras suas, a figura diabólica não tem um papel tão predominante.

O primeiro aspecto importante na obra em questão refere-se à caracterização externa do diabo. Na segunda parte da novela, o ser diabólico encarna-se na figura de um usurário que, além de viver em um bairro terrível, possui uma fisionomia sombria: "traços fortes [...], sua tez bronzeada [...], suas sobrancelhas [...] volumosas, seus olhos assustadores..." (GOGOL, 2000, p. 134). Logo em seguida, o pintor, que posteriormente pintará a figura do usurário, quando o enxerga, comenta sobre o semblante diabólico daquele: "o diabo!, é o diabo encarnado" (GOGOL, 2000, p.134). Já na primeira parte da narrativa, tem-se o personagem Tchartkov, jovem pintor que adquire - em uma pequena loja no mercado Stchúkin - o retrato de um homem com um semblante demoníaco. Na verdade, o quadro retrata o agiota acima mencionado. Os traços de tal figura contêm características freqüentemente atribuídas ao demônio, especialmente na aparência viva dos olhos. No trecho a seguir, Tchartkov observa na pintura a expressão excessivamente semelhante aos olhos do usurário: “aqueles olhos estavam realmente dotados de visão" (GÓGOL, 2000, p. 68). Logo, concretiza-se no personagem do agiota a figura do diabo que, como representação do duplo, provoca reações extremas no personagem, levando este a praticar atos repulsivos.

O segundo aspecto a ser considerado, relaciona-se com a maneira pela qual o duplo desperta o lado maléfico dos personagens. Dentro de uma perspectiva cristã, seguida pelo escritor, o diabo se impõe através da tentação, do apelo à mesquinharia, à trivialidade e a possibilidade de possuir os personagens . Assim, como nas escrituras do Antigo Testamento, a tentação torna-se o modo de ação do mais antigo satã que se tem notícia. Em $O$ retrato, Tchartkov encontra o quadro num momento delicado de sua vida, pois a atitude austera em relação a sua arte não o transformou em um artista famoso e rico. Portanto, a figura do usurário seduz o jovem pintor ao gosto pelo sucesso e pelo dinheiro. Logo depois de encontrar de forma estranha uma quantia de ouro junto ao retrato, Tchartkov vislumbra uma vida de conforto:

Tudo aquilo que ele havia contemplado até então com olhos de inveja, tudo aquilo que ele havia admirado de longe, [...], estava agora a seus pés. [...]. Vestir-se na última moda, fazer uma farra depois de todos aqueles longos dias de jejum, alugar um belo apartamento, ir seguidamente no teatro, aos cafés... (GOGOL, 2000, p. 91).

Em outra passagem, o protagonista se rende, também, à possibilidade de obter a glória com sua pintura: 
Sentiu brotar em si o desejo invencível de violentar a glória e de mostrar ao universo aquilo que era capaz. Acreditava já ouvir gritos:“ Tchartkov!, Tchartkov! Já viu o quadro de Tcharkov? Que pincelada firme e rápida! Que talento vigoroso!'(GOGOL, 2000, p. 92).

A partir desse momento, o personagem desiste da vida anônima e da relação rigorosa que mantinha com a sua arte, para entregar-se a uma produção comercial que lhe renderá fama e fortuna. Sob um prisma cristão, essa atitude é desprezível, visto que, além de se entregar aos bens mundanos, o personagem perde seu talento original. Na narrativa, isso se evidencia no momento em que o pintor tenta voltar a produzir uma arte mais bem elaborada. “... infelizmente, seus personagens, suas poses, seus grupos, tudo carecia de riqueza [...]. Por demasiado tempo seu pincel e sua imaginação haviam se fechado à banalidade" (GOGOL, 2000, p. 114).

Posteriormente, Tchartkov se encontra dominado pelo sentimento de inveja sempre que vê alguma obra que demonstre o talento de seu criador. O trecho abaixo que demonstra isso: "A inveja, uma inveja furiosa, tomou conta de Tchartkov. Quando via uma obra marcada pelo selo do talento, o fel subia ás suas faces, ele rangia os dentes e a devorava com um olhar rancoroso" (GOGOL, 2000, p. 116).

Após isso, o jovem pintor, possuído de raiva e inveja, empreende um projeto terrivelmente tenebroso. O protagonista começa a adquirir as mais belas obras de arte para depois destruí-las. Essa atitude se concretiza na passagem a seguir:

Começou a comprar tudo que a arte produzia de melhor. Após pagar muito caro por cada quadro, ele o levava [...] para casa e se atirava sobre ele como um tigre para o estraçalhar, fazendo o em pedaços, pisoteando-o enquanto dava gargalhadas de prazer. (GOGOL, 2000, p. 116).

Por fim, Tchartkov, tomado cada vez mais pela raiva, acaba febril e mentalmente perturbado, o que acaba levando o personagem à morte.

Podemos dizer que, em $O$ retrato, a manifestação da duplicidade se concretiza na figura do agiota que, em contato com os personagens, provoca-os a ter sentimentos pérfidos e a cometer atos repulsivos. Na verdade, Gogol identifica o mal nos comportamentos moralmente condenáveis. Com isso, o desejo excessivo pelo dinheiro e pela glória, a mentira, o sentimento exagerado de raiva e de inveja inspiram o indivíduo - em contato com o duplo a oprimir e a humilhar o próximo. Dessa forma, conclui-se que o duplo diabólico desperta no indivíduo os vícios que estão ocultos nas profundezas da alma.

Para finalizar, podemos resumir dizendo que a presença do duplo identifica-se nas diversas representações da morte - como no $K a$ egípcio e na morte-renascimento, por exemplo - e que, posteriormente, o tema da duplicidade será explorado sem a divisão interna 
do ser - como em passagens bíblicas e em peças da Antiguidade. A cisão do Eu passará a figurar a partir dos textos do Romantismo alemão, que tratarão $o$ duplo de forma fragmentada. E é nessa perspectiva de duplicidade que se insere $O$ retrato, de Nocolai Gogol, visto que o protagonista encontra no seu duplo, corporificado no retrato, a representação dos seus piores sentimentos.

\section{Referências}

DE GRÈVE, Claude e GOURG, Marianne. Nouvelles de Petersbourg - Gogol. Paris: Hatier, 1998

FERNANDEZ-BRAVO. Duplo. In: Brunel, Pierre (dir.). Dicionário de mitos literários. Rio de Janeiro: UnB, 1998 p.261 - 287.

FERRATER, Mora, José. Diccionario de filosofía. Barcelona: Ariel, 1984. 4 v.

GÒGOL, Nicolai. O retrato. Porto Alegre: L\&M Pocket, 2000

MELLO, Ana Maria Lisboa. As faces do duplo na literatura. In: INDURSKY, Freda e Campos, Maria do Carmo (Org.). Discurso, memória e identidade. Porto Alegre: Sagra-Luzatto, 2000 (ensaio PPG Letras; 15) p. 111 - 123.

MORIN, Edgar. O homem e a Morte. Rio de Janeiro: Imago, 1997.

TODOROV, Tzvetan. Introdução á literatura fantástica. São Paulo: Perspectiva, 1975. 